\title{
Quantitative determination and classification of energy drinks using near-infrared spectroscopy
}

\author{
Anita Rácz ${ }^{1,2}$, Károly Héberger ${ }^{1, *}$, Marietta Fodor ${ }^{2}$ \\ ${ }^{1}$ Plasma Chemistry Research Group, Research Centre for Natural Sciences, Hungarian Academy \\ of Sciences, H-1117 Budapest XI., Magyar Tudósok krt. 2. \\ ${ }^{2}$ Department of Applied Chemistry, Faculty of Food Science, Szent István University, \\ H-1118 Budapest XI., Villányi út 29-43.
}

* To whom correspondence should be sent:

E-mail address: heberger.karoly @ttk.mta.hu (Károly Héberger) 


\begin{abstract}
Almost a hundred commercially available energy drink samples from Hungary, Slovakia and Greece were collected for the quantitative determination of their caffeine and sugar content with FT-NIR spectroscopy and high performance liquid chromatography (HPLC). Calibration models were built with partial least squares regression (PLS-R). An HPLC-UV method was used to measure the reference values for caffeine content, while sugar contents were measured with the Schoorl method. Both the nominal sugar content (as indicated on the cans) and the measured sugar concentration were used as references. Although the Schoorl method has larger error and bias, appropriate models could be developed using both references. The validation of the models was based on sevenfold cross-validation and external validation. FT-NIR analysis is a good candidate to replace the HPLC-UV method, because it is much cheaper than any chromatographic method, while it is also more time-efficient. The combination of FT-NIR with multi-dimensional chemometric techniques like PLS-R can be a good option for the detection of low caffeine concentrations in energy drinks.
\end{abstract}

Moreover, three types of energy drinks that contain i) taurine, ii) arginine and iii) none of these two components, were classified correctly using principal component analysis and linear discriminant analysis. In fact, such classifications are important for the detection of adulterated samples and for quality control, as well. In this case more than a hundred samples were used for the evaluation. The classification was validated with cross-validation and several randomization tests (X-scrambling).

Keywords: energy drink, caffeine, sugar, classification, PCA, LDA, FT-NIR 


\section{Introduction}

Energy drinks are one of the most common functional beverages nowadays amongst commercially available soft drinks. The high caffeine concentration combined with a characteristic flavor, color and diverse and unique appearances has conquered the entire world in the past decades. On the other hand, energy drinks might carry dangerous side effects. They provide refreshment, good taste and energy for athletes, adolescents and students, who often consume them in large quantities, because they look like (especially in a $1.5 \mathrm{~L}$ bottle) and taste like common soft drinks. In most countries energy drinks are not prohibited for minors, which means that anybody can consume them uncontrollably.

In the past decade many publications have dealt with the two greatest risks, the caffeine and the sugar intake from energy drinks. Extreme caffeine intake can lead to hypertension, cardiac arrhythmia, liver and kidney problems in case of long-term consumption, besides the potential overdose symptoms [1]. Unregulated caffeine intake in the case of children and adolescents cannot solely cause cardiac abnormalities, but it can cause mood and behavioral disorders [2]. Heckman et al. also mentioned that caffeine intake can be dangerous for pregnant women. It can increase the risk of impaired fetal growth and decrease fertility [3]. Another paper draws attention to the sugar content of energy drinks, where the biggest problems are obesity and the risk of type 2 diabetes mellitus [4]. An average portion of energy drink contains $10 \mathrm{~g}$ sugar per $100 \mathrm{ml}$ liquid.

A new "trend" has shown up in the last years, which is quickly spreading amongst adolescents and college students: the combination of energy drinks with alcohol [5]. This combination can cause serious problems, for example the dehydration of the body caused by 
drinking alcohol is increased by the effect of caffeine. Ferreira et al. confirmed in their paper that, although the combination of energy drinks with alcohol can give a false feeling that the decrease of motor coordination has stopped, it cannot be detected in reality [6]. Another experiment with college students concluded that those students who consume energy drinks with alcohol have a higher risk to be involved in alcohol-related consequences [7].

As the consumption of energy drinks is an increasing and daily issue, especially in the case of adolescents, control of the caffeine and sugar content is of utmost importance for both the consumers and the producers. While every country has its own controlling and regularization systems, among the hundreds of energy drink brands one can assume that they are unregulated. There are plenty of methods reported in the literature for measuring the caffeine content of energy drinks, and one can find sources for the examination of sugar contents as well. Two types of experiments can be distinguished: spectrometric and chromatographic techniques. From the first group Armenta et al. used solid-phase Fourier-transform Raman spectrometry for the analysis of commercial energy drink samples [8] and in another paper an UV/VIS derivative spectrophotometric approach with solid phase extraction is presented [9]. As for the other group, one can successfully apply HPTLC-UV densitometric analysis [10], dispersive liquid-liquid microextraction (DLLME) with gas chromatography-nitrogen phosphorus detection (GC-NPD) [11] or surfactant-mediated matrix-assisted laser desorption/ionization time-of-flight mass spectrometry (MALDI-TOF-MS) for the determination of caffeine content, and also vitamins such as riboflavin, nicotinamide, etc. [12]. Some other examples are summarized (including those mentioned above) in Table $\mathbf{1}$ in detail. 
Table 1: Summary of the examples for the determination of caffeine and sugar content in energy drinks, soft drinks and coffees.

\begin{tabular}{|c|c|c|c|c|}
\hline Name & Method & Matrix & Components & Other \\
\hline $\begin{array}{l}\text { E. Abourashed } \\
\text { et al. }[10]\end{array}$ & $\begin{array}{l}\text { HPTLC-UV } \\
\text { densitometric } \\
\text { analysis }\end{array}$ & $\begin{array}{l}\text { energy } \\
\text { drinks, } \\
\text { herbal } \\
\text { products }\end{array}$ & caffeine & $\begin{array}{c}\text { recovery= } \\
98.90 \pm 3.46 \\
\text { accuracy= } \\
99.84 \pm 2.87\end{array}$ \\
\hline $\begin{array}{l}\text { S. Armenta et al. } \\
{[8]}\end{array}$ & $\begin{array}{c}\text { solid-phase FT- } \\
\text { Raman spectrometry }\end{array}$ & $\begin{array}{l}\text { energy } \\
\text { drinks }\end{array}$ & caffeine & $\begin{array}{l}\mathrm{LOD}=18 \\
\mathrm{mg} \mathrm{L}^{-1}\end{array}$ \\
\hline $\begin{array}{c}\text { C. Pieszko et al. } \\
\text { [9] }\end{array}$ & $\begin{array}{l}\text { UV/VIS derivative } \\
\text { spectrophotometry } \\
+ \text { solid phase } \\
\text { extraction }\end{array}$ & $\begin{array}{l}\text { energy } \\
\text { drinks }\end{array}$ & $\begin{array}{l}\text { caffeine, } \\
\text { taurine }\end{array}$ & $\begin{array}{c}\mathrm{LOD}=0.21 \\
\mathrm{LOQ}=0.63 \\
\mu \mathrm{g} \mathrm{mL}-1\end{array}$ \\
\hline $\begin{array}{c}\text { H. Sereshti et al. } \\
{[11]}\end{array}$ & $\begin{array}{c}\text { dispersive liquid- } \\
\text { liquid } \\
\text { microextraction } \\
\text { (DLLME) + gas } \\
\text { chromatography- } \\
\text { nitrogen phosphorus } \\
\text { detection (GC-NPD) }\end{array}$ & $\begin{array}{c}\text { tea, } \\
\text { coffee, } \\
\text { various } \\
\text { beverages }\end{array}$ & caffeine & $\begin{array}{c}\mathrm{LOD}=0.02 \\
\mathrm{LOQ}=0.05 \\
\mu \mathrm{g} \mathrm{mL}-1\end{array}$ \\
\hline $\begin{array}{l}\text { D. C. Grant } e t \\
\text { al. }[12]\end{array}$ & $\begin{array}{l}\text { surfactant-mediated } \\
\text { MALDI-TOF-MS }\end{array}$ & $\begin{array}{l}\text { energy } \\
\text { drinks }\end{array}$ & $\begin{array}{l}\text { caffeine, } \\
\text { riboflavin, } \\
\text { nicotinamide, } \\
\text { pyridoxine }\end{array}$ & $\begin{array}{c}\mathrm{RSD}<20 \\
\%\end{array}$ \\
\hline $\begin{array}{l}\text { B. Vochyánová } \\
\text { et al. [13] }\end{array}$ & $\begin{array}{l}\text { short-capillary } \\
\text { electrophoresis with } \\
\text { contactless } \\
\text { conductivity } \\
\text { detection }\end{array}$ & $\begin{array}{l}\text { energy } \\
\text { drinks }\end{array}$ & $\begin{array}{l}\text { sugar } \\
\text { content: } \\
\text { sucrose, } \\
\text { glucose, } \\
\text { fructose }\end{array}$ & $\begin{array}{c}\mathrm{LOD}=15 \\
\mathrm{LOQ}=52 \\
\mathrm{mg} \mathrm{L}^{-1} \text { for } \\
\text { sucrose }\end{array}$ \\
\hline $\begin{array}{l}\text { R. Lucena et al. } \\
\text { [14] }\end{array}$ & $\begin{array}{l}\text { continuous solid- } \\
\text { phase extraction }+ \\
\text { UV-Vis and ELSD } \\
\text { detectors }\end{array}$ & soft drinks & $\begin{array}{l}\text { total sugars, } \\
\text { class IV } \\
\text { caramel, } \\
\text { caffeine }\end{array}$ & $\begin{array}{c}\mathrm{RSD}=2.6 \\
\% \text { for } \\
\text { sucrose and } \\
\mathrm{RSD}=4 \% \\
\text { for caffeine }\end{array}$ \\
\hline $\begin{array}{l}\text { M. Aranda et al. } \\
\text { [15] }\end{array}$ & $\begin{array}{l}\text { planar } \\
\text { chromatography- } \\
\text { multiple detection }\end{array}$ & $\begin{array}{l}\text { energy } \\
\text { drinks }\end{array}$ & $\begin{array}{l}\text { riboflavin, } \\
\text { pyridoxine, } \\
\text { nicotinamide, } \\
\text { caffeine, } \\
\text { taurine }\end{array}$ & $\begin{array}{c}\text { RSD \% } \\
\text { between } \\
0.8 \text { and } 1.5 \\
\text { (all } \\
\text { substances } \\
\text { in matrix) }\end{array}$ \\
\hline $\begin{array}{l}\text { V. V. Khasanov } \\
\text { et al. [16] }\end{array}$ & $\begin{array}{c}\text { capillary } \\
\text { electrophoresis }(\mathrm{CE})\end{array}$ & $\begin{array}{l}\text { energy } \\
\text { drinks }\end{array}$ & $\begin{array}{l}\text { caffeine, } \\
\text { vitamin c, PP } \\
\text { and B6 }\end{array}$ & $\begin{array}{l}\text { relative } \\
\text { error: } 1.45 \\
-2.65 \%\end{array}$ \\
\hline
\end{tabular}


Although the mentioned methods can be used with success, they are time- and moneydemanding because of the necessary pretreatments, solvents and other required materials. In the field of spectroscopy, Fourier transformed near infrared spectroscopy is one of the fastest and cheapest techniques, which is commonly used in several research areas from pharmaceutical to food sciences. The method is easy to use and in most cases it does not need any sample pretreatment. We can find some publications in the literature for the determination of caffeine content with FT-NIR as well, but only for coffee samples $[17,18]$.

Therefore, our aim was to develop a novel, money- and time-saving method for the determination of caffeine and sugar concentration in energy drinks with FT-NIR spectroscopy. The technique has not been used earlier for this type of analysis and sample matrix. An easy HPLC-UV method was further developed from an international standard to provide a reference method for the determination of caffeine concentrations. While caffeine and sugar are the most important components, minor components such as taurine or arginine should not be ignored either. In Hungary, production of taurine-containing energy drinks is legally hindered, thus most of the producers are trying to avoid this component; it is either omitted altogether, or replaced with arginine. From this point of view, Hungarian energy drinks can be termed "carbonated soft drinks with high caffeine content" (which is currently the official term for them), as they differ from their American or other European counterparts. It has to be indicated on the bottles, which means that the quality control and verification of these energy drink samples are also important. Moreover, there are several producers, who distribute various products with different compositions. In this work, we have developed quantitative models, and classification analyses of energy drinks based on their most important ingredients and sugar content. 


\section{Materials and methods}

Samples

91 energy drink samples in total were used for the determination of sugar content. They contained 71 original, commercially available samples from Hungary, Slovakia and Greece. Some original samples were used only in one part of the experiments (for example just for caffeine concentration determination or for sugar concentration determination according to Schoorl) and others were used in all cases. (It was necessary to allow some overlap between the examinations, because the samples could not have been stored for longer periods unaltered.) The other samples were mixtures of the original ones. It was necessary to extend our dataset with mixtures, as we intended to cover the examined concentration range uniformly.

In the classifications, 108 samples were used to make a diverse dataset with specific minor components (taurine, arginine).

For the determination of caffeine content, 42 original samples and 33 mixtures were used. Most of the commercial samples in Hungary contain nominally 160 ppm or 320 ppm caffeine. Thus the concentration range between the minimum and maximum values was extended with mixtures (typical ratios were 1:1, 1:2, 1:3 and 1:4).

Sample preparation

For the HPLC-UV measurements the energy drink samples were sonicated in an ultrasonic bath (type T2MODX; VWR) for 20 minutes; then, $50 \mu 1$ of them was diluted to $1600 \mu \mathrm{l}$ with ultra-pure water in vials. External calibration with peak area integration was used 
for the quantification of total caffeine concentration in the energy drink samples. The calibration points were the following: 2.5, 5.0, 10.0, and $20.0 \mathrm{ppm}$ (because of the thirty-two-times dilution).

The only "sample pretreatment" step for FT-NIR analysis after the sonication was pouring the samples into $10 \mathrm{ml}$ vials.

High-performance liquid chromatography (HPLC-UV)

Methanol (MeOH; HPLC grade) was purchased from Scharlau (Barcelona, Spain). The caffeine standard ( $\geq 98 \%$ ) was obtained from the Sigma-Aldrich group (Schnelldorf, Germany). Ultra-pure water $(18.2 \mathrm{M} \Omega \mathrm{cm})$ was obtained from a Milli-Q system from Merck-Millipore (Milford, MA, USA).

The international standard for the determination of caffeine content in coffee and coffee products (ISO 20481:2008) was adapted for the energy drink samples. Briefly, an Agilent 1200 HPLC (Agilent Technologies, Santa Clara, CA, USA) system was used for the HPLC-UV based quantification of caffeine. An Agilent Zorbax XDB C ${ }_{18}$ HPLC column $(4.6 \mathrm{~mm} \times 150 \mathrm{~mm} \times 5.0$ $\mu \mathrm{m})$ was used in isocratic mode at $40^{\circ} \mathrm{C}$. The flow rate was $1 \mathrm{ml} \mathrm{min}^{-1}$, the injection volume was $20 \mu \mathrm{l}$, while the chromatographic run lasted for $18 \mathrm{~min}$. UV detection was carried out at $273 \mathrm{~nm}$, and additional peak purity measurements were executed at $260 \mathrm{~nm}$ in order to exclude samples containing impurities in the retention window of caffeine.

Fourier-transform near infrared spectroscopy (FT-NIR)

A Bruker $\mathrm{MPA}^{\mathrm{TM}}$ Multipurpose FT-NIR analyzer (Bruker Optik GmbH, Ettlingen, Germany) was used for FT-NIR measurements. The device is equipped with a quartz beam splitter; an integrated Rocksolid ${ }^{\mathrm{TM}}$ interferometer; a thermostated sample compartment equipped 
with a flow-through cuvette; a TE-InGaAs detector working in the 800-2500 nm wavelength range (12500-4000 $\mathrm{cm}^{-1}$ wavenumber). OPUS 6.5 (Bruker Optik GmbH, Ettlingen, Germany) software was integrated as a device manager. Transmission mode was used for the collection of absorption spectra. The spectral resolution was $8 \mathrm{~cm}^{-1}$, the scanner speed was $10 \mathrm{kHz}$ and each spectrum was the average spectrum of 32 subsequent scans. The samples were measured three times, and averages were used for the further analysis. Derivation and standardization of the spectra were used as data pretreatment methods in each case of model building.

\section{Partial least-squares regression (PLS-R)}

Partial least-square regression is one of the most commonly used multivariate regression techniques. One of the most understandable and explanatory papers about PLS-R is the work of P. Geladi and B. R. Kowalski [19]. Soon after being published, PLS-R became more and more popular in the field of chemistry. The method is based on the regression between the PLS components of the $\mathrm{X}$ (independent) and $\mathrm{Y}$ (dependent) variables. There is an interrelation between the PLS components of the $\mathbf{X}$ and $\mathbf{Y}$ matrices, which can be assigned to the regression coefficient, b. The number of latent variables (PLS components) is really important, if it is not chosen in a proper way, then one can easily over- or underfit the model. One commonly used method for choosing the optimal number is the minimum value of the root mean squared error of cross-validation (RMSECV):

$$
R M S E C V=\sqrt{\frac{\sum_{i=1}^{N}\left(\hat{y}_{C V, i}-y_{i}\right)^{2}}{N}}
$$


where $\hat{y}_{C V, i}$ denotes the predicted y values with cross-validation, $y_{i}$ is the measured y value and $N$ is the number of samples [20].

The validation of the regression models is also important. Sevenfold cross-validation, leave-oneout cross-validation, internal test validation and external validation are the most common techniques. However, cross-validation is probably the most widely used method for estimating prediction error [21]. The goodness of the final regression models is determined with several commonly used performance parameters like $R^{2}, Q^{2}, R M S E C V$, etc. $R^{2}$ is the coefficient of determination for the calibration model, which can be calculated with the following equation [22]:

$$
R^{2}=1-\frac{\sum_{i=1}^{n}\left(y_{i}-\hat{y}_{i}\right)^{2}}{\sum_{i=1}^{n}\left(y_{i}-\bar{y}_{i}\right)^{2}}=1-\frac{R S S}{T S S}
$$

where $y_{i}$ is the measured y value, $\hat{y}_{i}$ is the predicted y value and $\bar{y}_{i}$ is the mean of the measured y values. $Q^{2}$ is calculated with the same equation as $R^{2}$, but from the validation data. $R S S$ is the residual sum of squares and TSS is the total sum of squares. OPUS 6.5 [23] was applied for PLSR model building.

Linear discriminant analysis (LDA) with the use of principal component (PC) scores

Linear discriminant analysis is another popular technique in the field of classification methods [24]. It is a supervised method, i.e. we must know the class memberships before the analysis. It is similar to principal component analysis (PCA), but here canonical variables (roots) are calculated, and ellipses (or hyperellipsoids) are plotted around the points of the groups. The 
discriminant function is defined as a line, which connects the intersections of the ellipses. If the number of groups is $N$, the number of canonical variables is $N-1$.

LDA has a limitation in the number of variables, but PCA can compress the information into a smaller number of variables, which can easily be used in linear discriminant analysis to replace the original variables. Principal component analysis [25] can be thought of as the pair of PLS-R in the multidimensional pattern recognition world, in terms of being as popular as PLS-R. However, it cannot be used as a classification method, but only to recognize different patterns and groupings in our dataset without the use of any dependent (grouping) variable(s). The basic idea of this method is the following: the original dataset can be decomposed into two matrices, $\mathbf{P}$ and $\mathbf{T}$, where $\mathbf{P}$ contains the loadings and $\mathbf{T}$ contains the score vectors. The loading and score vectors are calculated from the linear combinations of the original variables using orthonormality as a constraint. The principal components explain parts of the variance in the original data matrix in decreasing order.

STATISTICA 12 [26] was applied for both the PCA and LDA analyses.

\section{Results and discussion}

\section{Determination of caffeine content}

The 42 original energy drink samples were measured first with the HPLC-UV method. The other 33 mixtures were prepared from the original ones. Since we knew the exact concentration values and the used amounts in the mixtures, only a few mixture samples were checked again with HPLC. Relative standard deviations were calculated for these samples: the 
proportional error differences of standard deviation were below $5 \%$ (5\% threshold was chosen by the authors). Every sample was measured three times with HPLC-UV and then the average of the calculated caffeine concentrations were used for the FT-NIR measurements as reference values. Peak purity was also checked for the method: the samples were measured at $260 \mathrm{~nm}$, as well. The results were compared with the original measurements at $270 \mathrm{~nm}$, and there were no significant differences according to the $t$ test (the predefined error limit was $5 \%$ ). The running time of the HPLC-UV analysis was 18 minutes. The retention time for the caffeine peak was around 9.5 minutes. One of the measured chromatograms can be seen on Figure $\mathbf{1}$ as an example.

\section{Figure 1}

Every sample was examined three times from $10 \mathrm{ml}$ vials with a quartz flow cuvette with the FT-NIR analyzer. Figure 2 shows an example of the measured spectra and its derivative form. The concentration range of caffeine was between 118 and 338 ppm, based on HPLC-UV determination. This measurement was really delicate because the caffeine concentration was really low in the samples compared to other components.

\section{Figure 2}

Principal component analysis was used for spectral outlier detection. There was no spectral outlier in our dataset, thus the final number of samples was 75 . Then, the models were optimized with different wavelength selections and data preprocessing methods in OPUS 6.5 software. The applied data preprocessing methods were derivation and standardization (standard normal variate). The number of smoothing points was 17. The selected wavenumber ranges were: $12490-7498,6102-5446$ and $4605-4243 \mathrm{~cm}^{-1}$. The number of latent variables was 
eight, which was chosen by the global minimum of the root mean squared error of cross validation $(R M S E C V)$.

Figure 3 shows the final sevenfold cross-validated model. Sevenfold cross-validation is an appropriate and common validation procedure suggested in ref. [21].

\section{Figure 3}

The coefficient of determination, $R^{2}$ of the calibration model was $96.63 \%$ and the root mean squared error of calibration (RMSEC) was $13.4 \mathrm{ppm}$. RMSEC values were calculated with the following equation:

$$
R M S E C=\sqrt{\frac{\sum_{i=1}^{N}\left(\hat{y}_{i}-y_{i}\right)^{2}}{(N-A-1)}}
$$

Where $\hat{y}_{i}, y_{i}$ and $N$ is the same as in Eq. 1., $A$ is the number of latent variables [20].

In the case of cross-validation, $\mathrm{Q}^{2}$ (determination coefficient of the cross-validated model) was $92.79 \%$ and the root mean squared error of cross-validation was $18.3 \mathrm{ppm}$.

Finally, external validation was carried out with 13 commercially available new energy drink samples, as the final verification of our model. Here the externally validated counterpart of $R^{2}$, the $Q^{2}$ value reached $89.81 \%$ and the root mean squared error of prediction (RMSEP) value was $36.3 \mathrm{ppm}$. (The smaller degree of freedom causes higher prediction error.) RMSEP values are calculated with the following equation:

$$
R M S E P=\sqrt{\frac{\sum_{i=1}^{N_{p}}\left(\hat{y}_{i}-y_{i}\right)^{2}}{N_{p}}}
$$

Where $\hat{y}_{i}$ and $y_{i}$ are the same as in Eqs 1 and 2. The number of samples in the validation or external test set is denoted with $N_{p}[20]$. 
The selected spectral areas can be assigned to functional groups and bonds such as methyl antisymmetric and symmetric stretch $1^{\text {st }}$ and $2^{\text {nd }}$ overtones [27], $1^{\text {st }}$ overtone of $\mathrm{C}-\mathrm{O}$ and $\mathrm{N}-\mathrm{H}$ or $\mathrm{CONH}$ amide combination bands [28,29].

\section{Determination of sugar content}

71 original and 20 mixed samples (91 in all) were used for the determination of sugar content in the energy drinks. The mixture samples were made from the original ones with the use of different mixing ratios. (The producers prefer the usage of dedicated few typical sugar concentrations; thus, we had to extend the number of samples with mixtures for a better coverage.)

The Schoorl method was used as the reference for the determination of sugar concentration. This method is frequently used for the determination of sugar content in food analysis. The applied technique was based on an AOAC standard [30]. 75 of the 91 samples were chosen and measured in this way. However, the method has a large bias and relatively large standard deviation (namely $12.4 \%$ ), especially in the range of small amounts of sugar (1-2 $\mathrm{g} / 100 \mathrm{ml}$ ). Thus we decided to use and compare both of the original (indicated on the can) and the measured values, because the nominal concentrations have less error (based on a simple weighing).

In this case every sample was analyzed three times from $10 \mathrm{ml}$ vials in a quartz flow cuvette with an FT-NIR analyzer, as well. The average of the spectra was used for further chemometric analysis. First, PCA was applied to detect spectral outliers. The result is shown in 
Figure 4. Only two samples from the 91 were out of the $95 \%$ confidence range (Hotelling-T ellipse).

\section{Figure 4}

PLS regression was used for model building. The model optimization for the 89 samples was carried out with OPUS 6.5; first derivative and standardization (standard normal variate) were used for data preprocessing. The concentration range for sugar was between 0.0 and 14.9 $\mathrm{g} / 100 \mathrm{ml}$. Six latent variables were enough for model building, based on the global minimum of the RMSECV curve (like in the previous case). Two spectral ranges were chosen for the regression analysis: $7506-6796$ and $4605-4243 \mathrm{~cm}^{-1}$ (141 variables). The $R^{2}$ value for the calibration set was $99.75 \%$ and the RMSEC value was $0.219 \mathrm{~g} / 100 \mathrm{ml}$. The values were calculated in the same way as in the previous case (Eqs 2 and 3.).

\section{Figure 5}

Sevenfold cross-validation and external test validation were used as validation procedures

for our model. Figure 5 shows the result of cross-validation. In this case $Q^{2}$ was $99.54 \%$ and RMSECV was $0.29 \mathrm{~g} / 100 \mathrm{ml}$. Twelve new samples were used for the external validation of the model. Quite convincing results were obtained: $Q^{2}$ was $99.58 \%$ and $R M S E P$ was $0.26 \mathrm{~g} / 100 \mathrm{ml}$. In other words, in each case the root mean squared error of the model was under $0.3 \mathrm{~g} / 100 \mathrm{ml}$.

The selected peak areas can be assigned to functional groups and bonds such as the $1^{\text {st }}$ overtone of $\mathrm{OH}$ stretching or the combination of $\mathrm{CH}$ stretching and $\mathrm{CH}_{2}$ deformation bands [27].

Model building was repeated with the reference dataset based on the sugar content measurements. The two spectral outliers (as in the previous case) were omitted from the dataset, thus the final number of samples was 73 . In this case the component range extends between 0.1 
and $15.3 \mathrm{mg} / 100 \mathrm{ml}$. Again, first derivative and standardization (standard normal variate) were used as data preprocessing methods. Two spectral ranges were chosen for the regression analysis: $4506-4243 \mathrm{~cm}^{-1}$ and $7506-5446 \mathrm{~cm}^{-1}$. The variable selection method and also the PLS regression use the information of the $\mathbf{Y}$ (dependent) variables. Thus, the chosen intervals are slightly differed from the previous case $\left(7506-6796 \mathrm{~cm}^{-1}\right)$. The above ranges contain the vibration bands expected from theory and earlier examinations. Six PLS components were used for model building, which were chosen based on the global minimum of RMSECV values. Figure 6 shows the final validation model. Sevenfold cross-validation was used for validation.

\section{Figure 6}

The $R^{2}$ value for the calibration was $94.25 \%$ and $R M S E C$ was $1.00 \mathrm{~g} / 100 \mathrm{ml}$. After the validation process, the $Q^{2}$ value was $91.87 \%$ and $R M S E C V$ was $1.13 \mathrm{~g} / 100 \mathrm{ml}$. Eleven new samples were used for the external validation step. In this case the $Q^{2}$ value was $93.51 \%$ and RMSEP was $1.23 \mathrm{~g} / 100 \mathrm{ml}$. These results are also acceptable and useful, but in comparison with the previous results, we can conclude that it contains larger error. It is not surprising, because the measurement of sugar content has large bias and error (the standard deviation was $12.4 \%$ based on duplicates), which is much bigger than the error of a simple weighting. When the nominal values indicated on the cans were used, smaller errors were observed.

The detailed summary of the model performance parameters can be seen in Table 2 . The basic statistics table and histograms of the reference values (for every models) are shown in the electronic supplementary material as Figure S1. The values are not normally distributed, because some concentration segments have greater popularity amongst the producers. The data sets are available from the authors upon request. 
Table 2: Summary of the final regression models for caffeine and sugar content determination in energy drinks.

\begin{tabular}{|c|c|c|c|c|c|c|c|}
\hline & $\mathbf{N}$ & $\mathbf{C}^{\mathbf{b}}$ & $\boldsymbol{R}^{2, \boldsymbol{c}}$ & $\boldsymbol{Q}^{2}{ }_{\text {ext }}^{\mathbf{c}}$ & $\boldsymbol{Q}^{2, \mathbf{c}}$ & $\boldsymbol{R M S E C V}$ & $\boldsymbol{R M S E P}^{\boldsymbol{a}}$ \\
\hline Caffeine model & 75 & 8 & 96.63 & 94.94 & 92.79 & 13.4 & 16.8 \\
\hline Sugar model (with measured conc.) & 73 & 6 & 94.25 & 93.51 & 91.87 & 1.13 & 1.23 \\
\hline Sugar model (with nominal conc.) & 89 & 6 & 99.75 & 99.58 & 99.51 & 0.29 & 0.26 \\
\hline
\end{tabular}

${ }^{a}$ The unit of the RMSECV and RMSEP values in the case of sugar models were $\mathrm{g} / 100 \mathrm{ml}$. The unit of the RMSECV and RMSEP values in the case of caffeine model was ppm.

${ }^{\mathrm{b}} \mathrm{C}$ is the number of used PLS components.

${ }^{\mathrm{c}}$ The unit of performance parameters is $\%$.

\section{Classification of energy drinks}

In this part of the study FT-NIR spectra of 108 energy drinks samples were evaluated with PCA and LDA. LDA is a commonly used supervised pattern recognition technique in many field of science. It is simpler compared to others, such as machine learning or tree-based methods. With the use of PCA as a "data reduction" technique, we could eliminate the limitation of the number of variables. The aim of the evaluation was to classify the energy drinks into three groups, based on whether i) it contains arginine, ii) it contains taurine or iii) there is no taurine and arginine in the samples. As it was mentioned in the introduction, some producers replace taurine with arginine on such markets as Hungary, and some of them simply omit taurine. Samples from Slovakia, Greece and Hungary were used for the qualitative determination of energy drinks. 
In the first step, the average spectra of the samples from 12500 to $4000 \mathrm{~cm}^{-1}$ were used for principal component analysis. Standardization (standard normal variate) was applied as data preprocessing. After that the first twenty PCA scores were used for the further analysis with LDA.

LDA, as implemented in Statistica ${ }^{\mathrm{TM}}$ (Tulsa, Oklahoma, USA) has different options to choose the significant variables for model building, such as forward stepwise, backward stepwise or all effects. Forward stepwise model building method and threefold cross-validation were applied in the evaluation. Proper validation is very important; it should be tested, whether the results are artefacts or not. For this purpose as another validation method for the model, Xscrambling randomization test was used three times. Figure 7ab shows the final result with the comparison of a typical example for X-scrambling validation model. The three earlier mentioned groups can be clearly classified based on LDA and PCA analysis (and only FT-NIR spectra) and the validation of the model returned good results as well. The correct classification rate of the cross-validated model was $95.68 \%$.

\section{Figure 7ab}

\section{Conclusion}

The application of FT-NIR spectroscopy for the quantitative determination of caffeine and sugar concentrations in energy drinks is a great opportunity, not just because it saves time and money, but all of the validated models' $R^{2}$ values are above the $90.0 \%$ level (see details in Table 2). The models can replace HPLC and other frequently used (but time- and moneyconsuming) methods in the field of the determination of caffeine and sugar concentration. Almost a hundred energy drink samples were examined, thus these models cover virtually the 
whole market of commercial energy drinks in Hungary. In the case of sugar content determination, we can reach better models with the use of nominal concentrations, instead of using the Schrool-method; it means that the latter method has a larger bias than the simple weighing.

The samples with arginine, taurine or without them were clearly classified with PCA and LDA analysis with a $95.7 \%$ correct classification rate. The classification of these samples based on our grouping system can be used for the verification and detection of adulteration of the energy drinks. This type of classification of energy drinks is unique in the literature.

\section{Acknowledgements}

The authors would like to thank Dr. Mihály Dernovics and Andrea Vass for their help and the useful advices in HPLC-UV measurements and Csilla Biróova for her help in sugar content measurements.

\section{Conflict of Interest}

The authors declare that they have no conflict of interest. 


\section{References}

[1] Reissig CJ, Strain EC, Griffiths RR. Caffeinated energy drinks-A growing problem. Drug Alcohol Depend. 2009;99:1-10.

[2] Seifert SM, Schaechter JL, Hershorin ER, Lipshultz SE. Health effects of energy drinks on children, adolescents, and young adults. Pediatrics. 2011;127:511-28.

[3] Heckman MA, Weil J, de Mejia EG. Caffeine (1, 3, 7-trimethylxanthine) in foods: A comprehensive review on consumption, functionality, safety, and regulatory matters. J Food Sci. 2010;75:77-87.

[4] Malik VS, Schulze MB, Hu FB. Intake of sugar-sweetened beverages and weight gain : a systematic review. Am J Clin Nutr. 2006;84:274-88.

[5] Malinauskas BM, Aeby VG, Overton RF, Carpenter-Aeby T, Barber-Heidal K. A survey of energy drink consumption patterns among college students. Nutr J. 2007;6:35.

[6] Ferreira SE, de Mello MT, Pompéia S, de Souza-Formigoni MLO. Effects of energy drink ingestion on alcohol intoxication. Alcohol Clin Exp Res. 2006;30:598-605.

[7] O'Brien MC, McCoy TP, Rhodes SD, Wagoner A, Wolfson M. Caffeinated cocktails: Energy drink consumption, high-risk drinking, and alcohol-related consequences among college students. Acad Emerg Med. 2008;15:453-60.

[8] Armenta S, Garrigues S, de la Guardia M. Solid-phase FT-Raman determination of caffeine in energy drinks. Anal Chim Acta. 2005;547:197-203.

[9] Pieszko C, Baranowska I, Flores A. Determination of energizers in energy drinks. J Anal 
Chem. 2010;65:1228-34.

[10] Abourashed EA, Mossa JS. HPTLC determination of caffeine in stimulant herbal products and power drinks. J Pharm Biomed Anal. 2004;36:617-20.

[11] Sereshti H, Samadi S. A rapid and simple determination of caffeine in teas, coffees and eight beverages. Food Chem. 2014;158:8-13.

[12] Grant DC, Helleur RJ. Simultaneous analysis of vitamins and caffeine in energy drinks by surfactant-mediated matrix-assisted laser desorption/ionization. Anal Bioanal Chem. 2008;391:2811-8.

[13] Vochyánová B, Opekar F, Tůma P, Štulík K. Rapid determinations of saccharides in highenergy drinks by short-capillary electrophoresis with contactless conductivity detection. Anal Bioanal Chem. 2012;404:1549-54.

[14] Lucena R, Cárdenas S, Gallego M, Valcárcel M. Continuous flow autoanalyzer for the sequential determination of total sugars, colorant and caffeine contents in soft drinks. Anal Chim Acta. 2005;530:283-9.

[15] Aranda M, Morlock G. Simultaneous determination of riboflavin, pyridoxine, nicotinamide, caffeine and taurine in energy drinks by planar chromatography-multiple detection with confirmation by electrospray ionization mass spectrometry. J Chromatogr A. $2006 ; 1131: 253-60$.

[16] Khasanov V V., Slizhov YG, Khasanov V V. Energy drink analysis by capillary electrophoresis. J Anal Chem. 2013;68:357-9.

[17] Huck CW, Guggenbichler W, Bonn GK. Analysis of caffeine, theobromine and 
theophylline in coffee by near infrared spectroscopy (NIRS) compared to highperformance liquid chromatography (HPLC) coupled to mass spectrometry. Anal Chim Acta. 2005;538:195-203.

[18] Zhang X, Li W, Yin B, Chen W, Kelly DP, Wang X, et al. Improvement of near infrared spectroscopic (NIRS) analysis of caffeine in roasted arabica coffee by variable selection method of stability competitive adaptive reweighted sampling (SCARS). Spectrochim Acta - Part A Mol Biomol Spectrosc. 2013;114:350-6.

[19] Geladi P, Kowalski BR. Partial least-squares regression: a tutorial. Anal Chim Acta. $1986 ; 185: 1-17$.

[20] Naes T, Isaksson T, Fearn T, Davies T. Validation. A user-friendly Guid. to Multivar. Calibration Classif., Chicester: NIR Publications; 2002, pp. 155-75.

[21] Hastie T, Tibshirani R, Friedman J. Model Assessment and Selection. Elem. Stat. Learn. Data Mining, Inference, Predict., Springer, New York; 2001, pp. 214-6.

[22] Rácz A, Bajusz D, Héberger K. Consistency of QSAR models: Correct split of training and test sets, ranking of models and performance parameters. SAR QSAR Environ Res. 2015;26:683-700.

[23] Bruker Corporation, Billerica, MA U. OPUS 6.5 n.d.

[24] Hastie T, Tibshirani R, Friedman J. Linear Methods for Classification. Elem. Stat. Learn. Data Mining, Inference, Predict., Springer, New York; 2001, pp. 84-90.

[25] Wold S, Esbensen K, Geladi P. Principal component analysis. Chemom Intell Lab Syst. 1987;2:37-52. 
[26] Statsoft Inc., Tulsa, OK U. STATISTICA 12 n.d.

[27] Workman J, Jr. Functional groupings and calculated locations in wavenumbers (cm-1) for IR spectroscopy. Handb. Org. Compd. NIR, IR, Raman, UV-Vis Spectra Featur. Polym. Surfactants, San Diego: Academic Press; 2000, pp. 229-36.

[28] Magalhães LM, Machado S, Segundo MA, Lopes JA, Páscoa RNMJ. Rapid assessment of bioactive phenolics and methylxanthines in spent coffee grounds by FT-NIR spectroscopy. Talanta. 2016;147:460-7.

[29] Ribeiro JS, Ferreira MMC, Salva TJG. Chemometric models for the quantitative descriptive sensory analysis of Arabica coffee beverages using near infrared spectroscopy. Talanta. 2011;83:1352-8.

[30] Horovitz W. Sugar and Sugar products. Off. methods Anal. Assoc. Off. Anal. Chem., Washington, USA: AOAC; 1975, p. 573. 
Figure 1: One example of the measured chromatograms. The retention time and area are written above the caffeine peak.

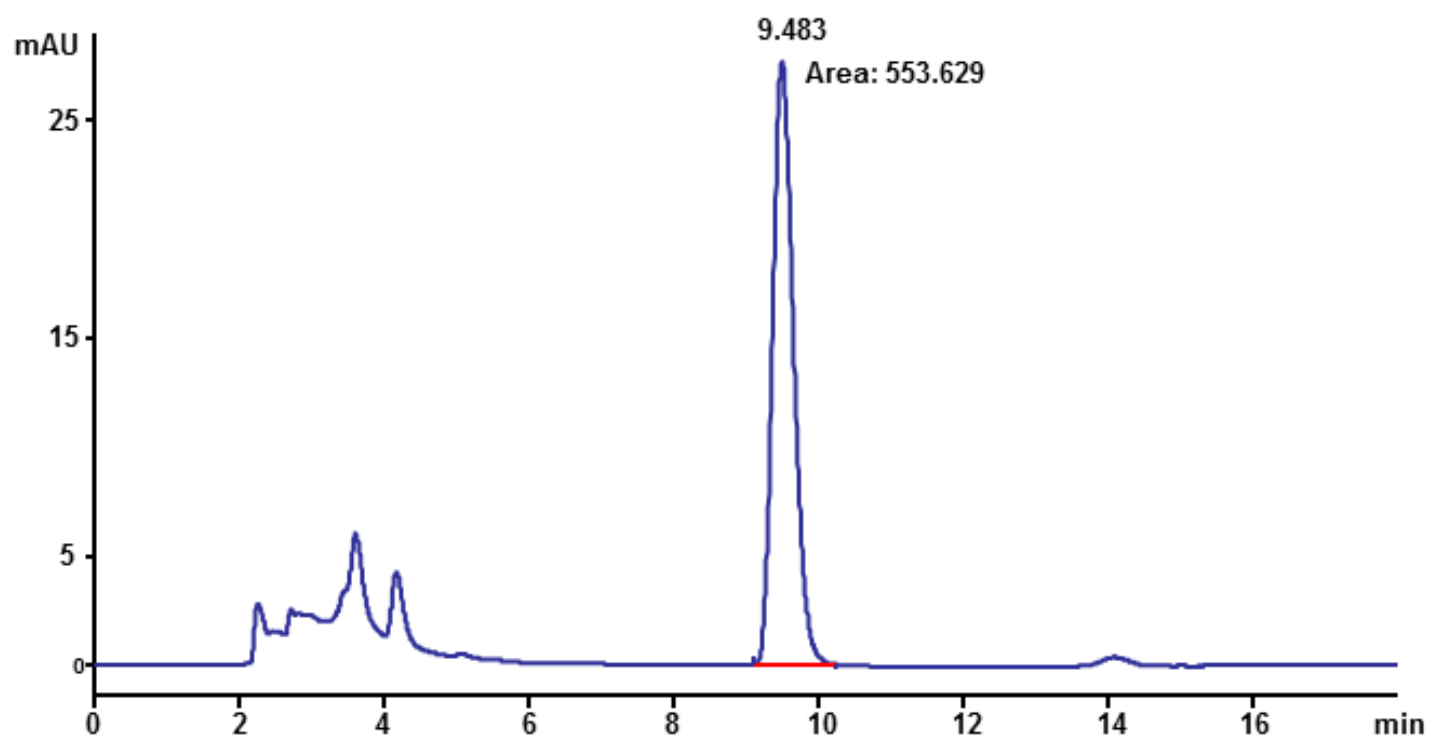

Figure 2: An example of the measured samples spectra and its derivative form. Absorbance is plotted on the left $\mathrm{Y}$ axis, first derivative absorbance on the right $\mathrm{Y}$ axis and wavenumbers are on the $\mathrm{X}$ axis. The original spectrum is marked with blue and the derivative is marked with red.

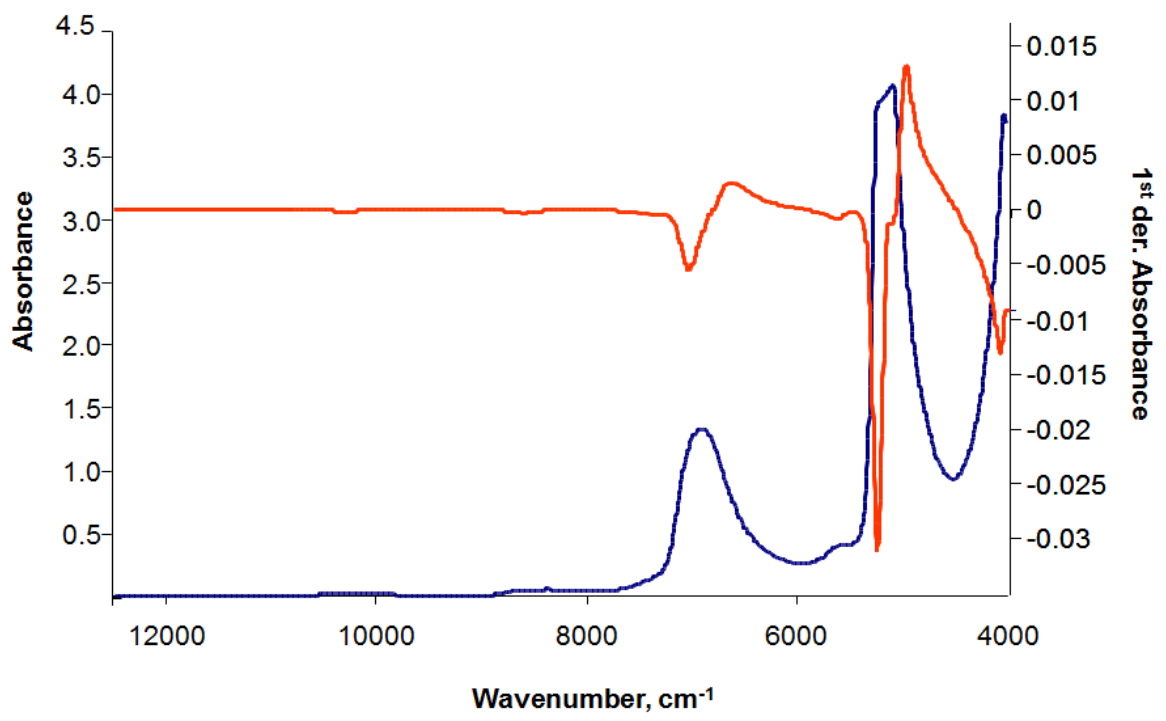


Figure 3: The final validated model for caffeine. Predicted $Y$ values are plotted against measured Y values.

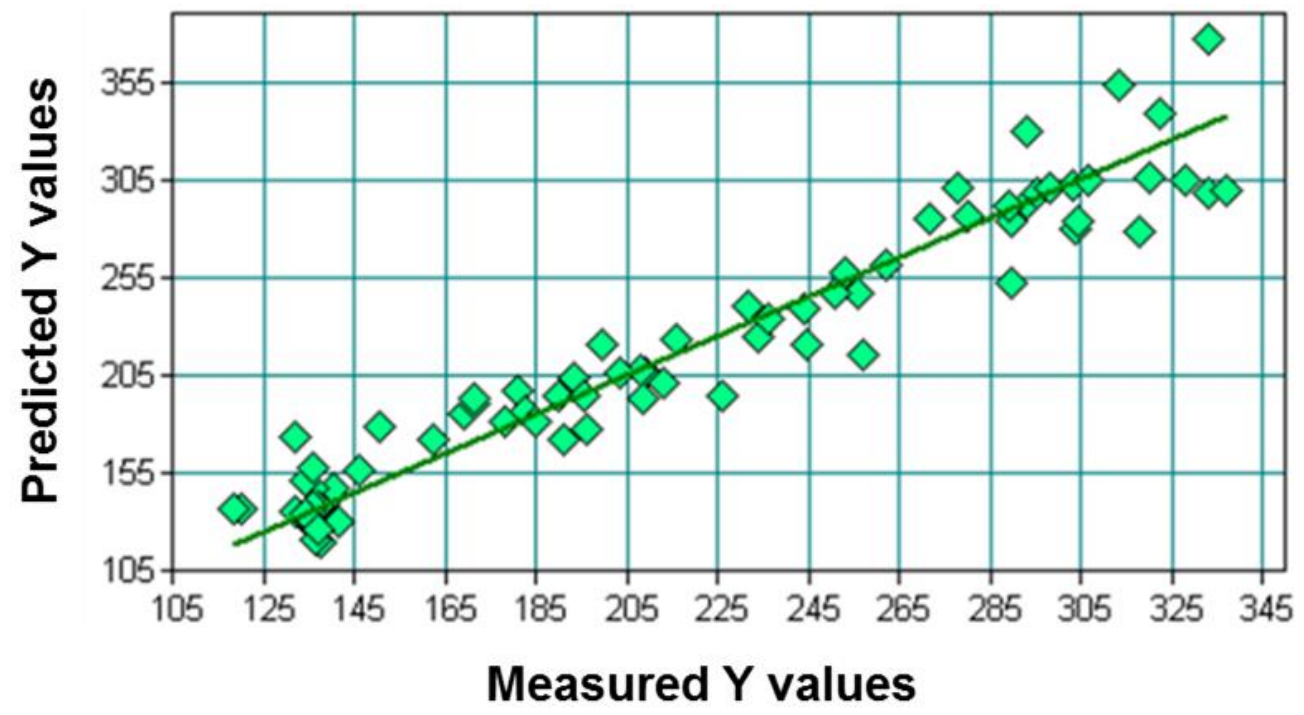

Figure 4: Spectral outlier detection in the case of sugar content determination. The second principal component score is plotted against the first one. The Hotteling-T ${ }^{2}$ ellipse is marked with a red dotted line.

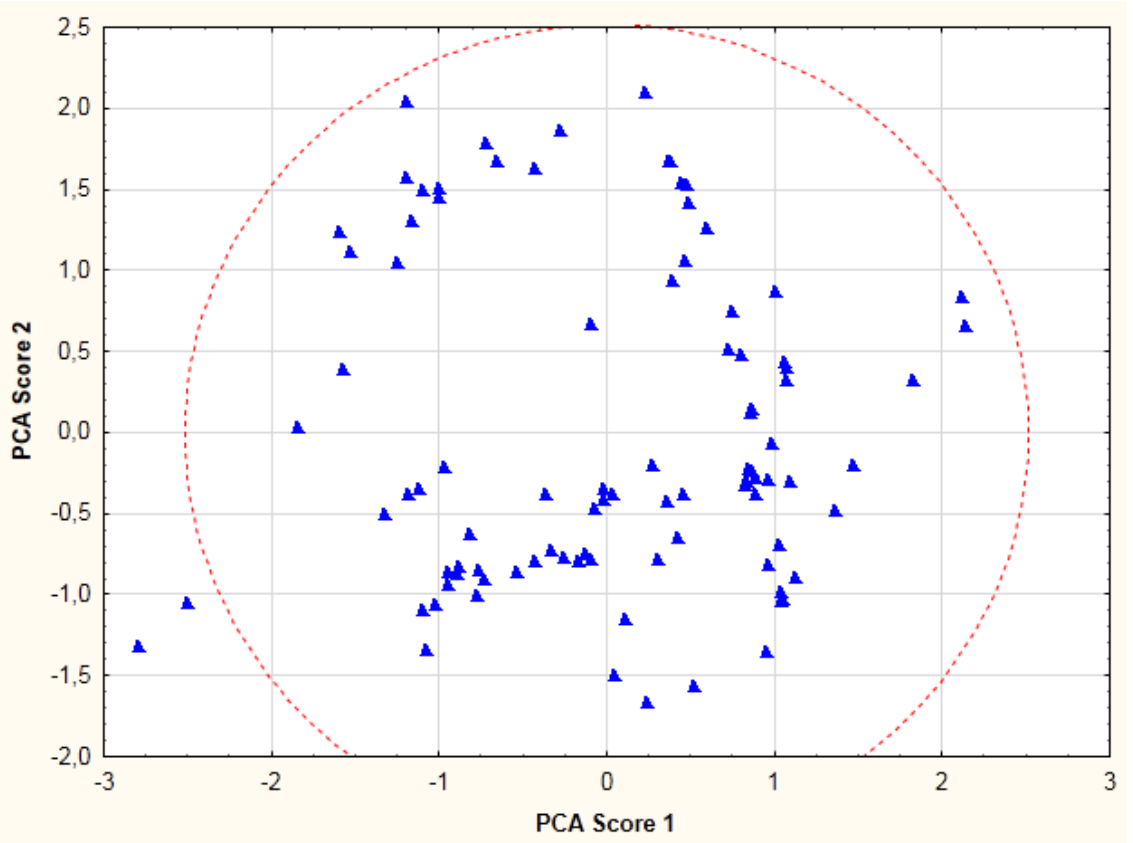


Figure 5: The final validated model for the sugar content determination based on the nominal values (indicated on the cans). Predicted $\mathrm{Y}$ values are plotted against the nominal $\mathrm{Y}$ values.

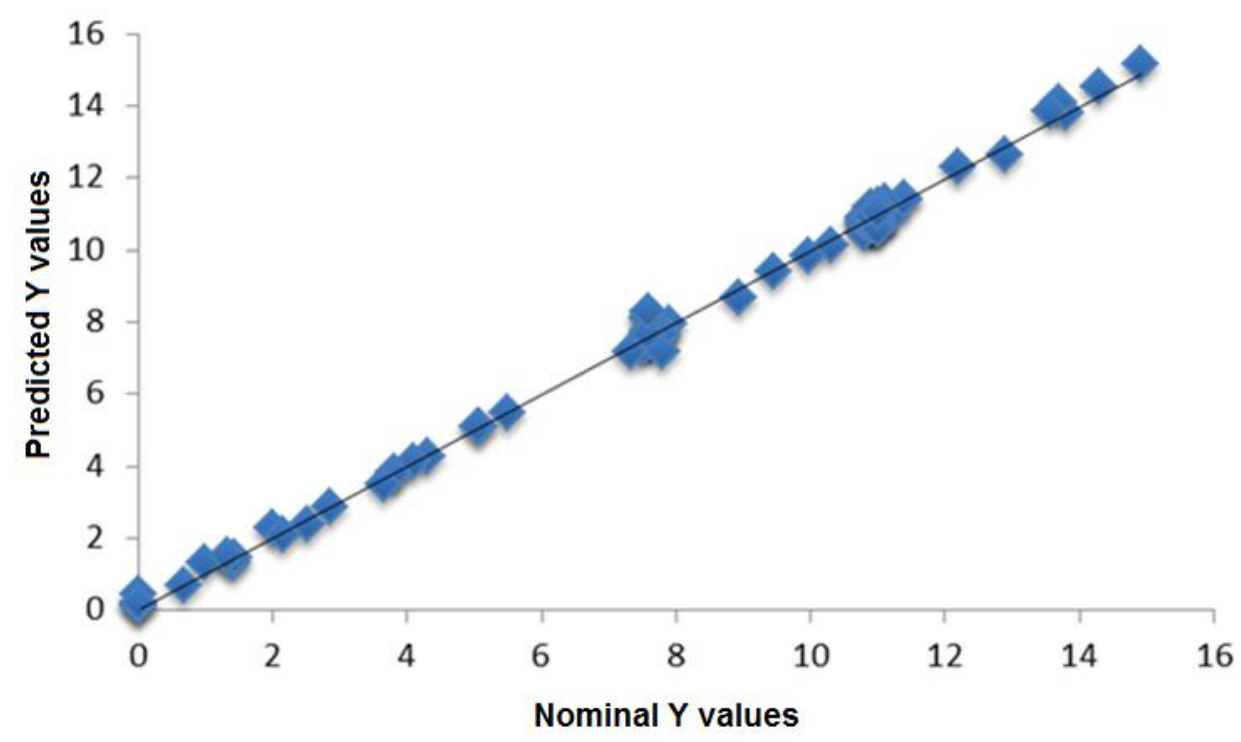

Figure 6: The final validated model for the sugar content determination based on the measured values (Schoorl method). Predicted Y values are plotted against the measured Y values.

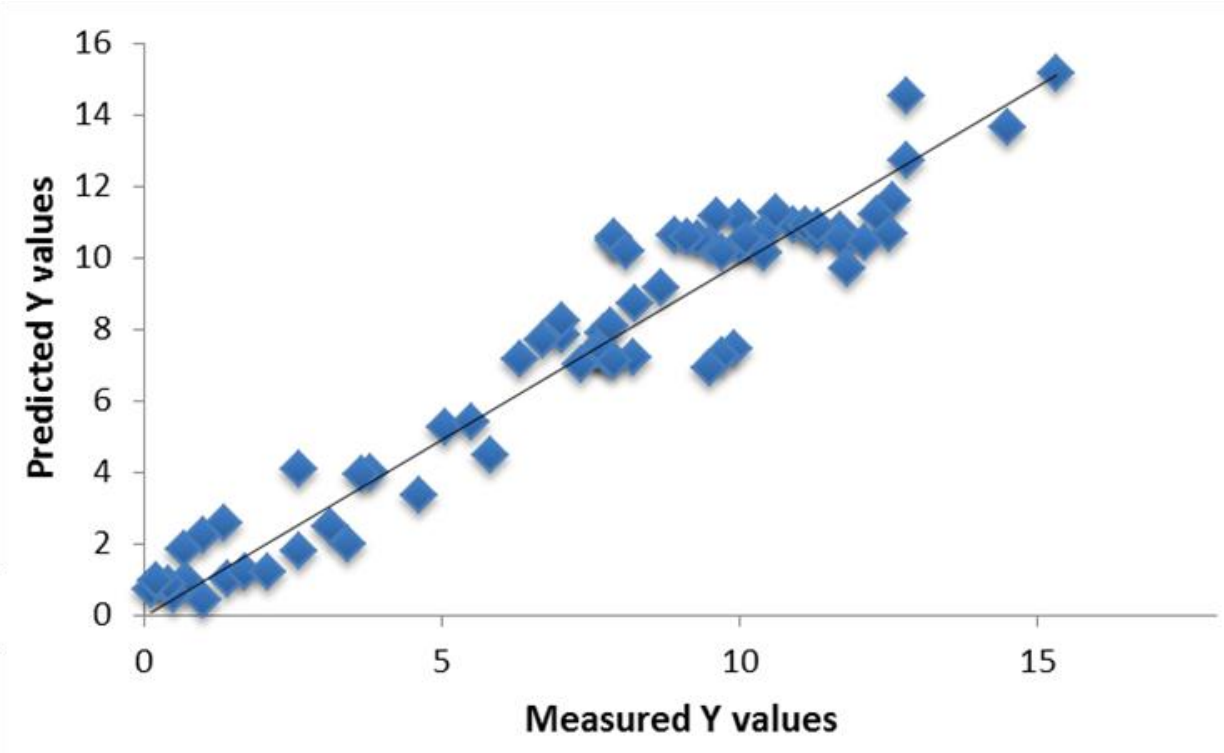


Figure 7a,b: (a) The final classification model for the original (without taurine or arginine), taurine and arginine groups of samples. (b) The same model with the use of X-scrambled data as randomization test. The second canonical variable is plotted against the first one.
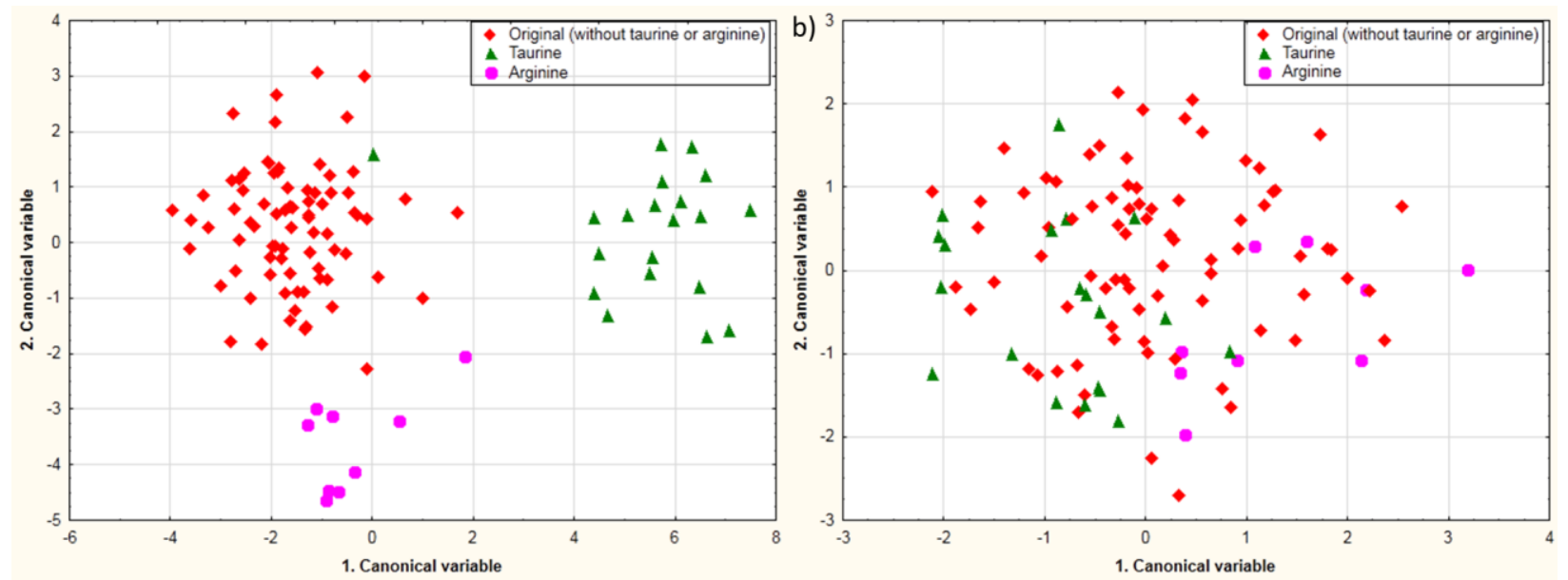